\title{
Transcription Initiation Factor TFIID Subunit 5
}

National Cancer Institute

\section{Source}

National Cancer Institute. Transcription Initiation Factor T FIID Subunit 5. NCI Thesaurus.

Code C30066.

Transcription initiation factor TFIID subunit 5 ( $800 \mathrm{aa}, \sim 87 \mathrm{kDa}$ ) is encoded by the human TAF5 gene. This protein plays a role in the assembly of the basal transcription apparatus. 